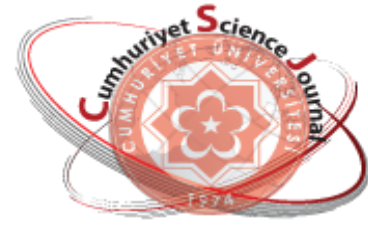

e-ISSN: $2587-246 X$

ISSN: 2587-2680

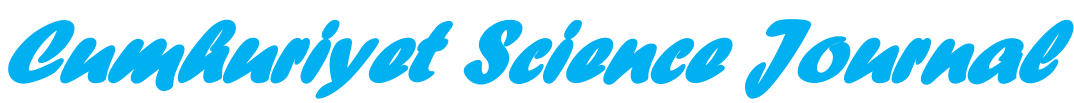

$\cos 7$

Cumhuriyet Sci. J., Vol.40-1(2019) 24-34

\title{
Selfadjointness and Positiveness of the Differential Operators Generated by New Type Sturm-Liouville Problems
}

\author{
Hayati OL $\breve{G} A R$ \\ Gaziosmanpasa University, Faculty of Science Department of Mathematics, Tokat, TURKEY
}

Received: 06.08.2018; Accepted: 27.12.2018

http://dx.doi.org/10.17776/csj.451174

\begin{abstract}
It is purpose of this paper to investigate Sturm-Liouville equation $-u^{\prime \prime}(x)+q(x) u(x)=\lambda u(x)$ on many-interval $\left[\alpha, \gamma_{1}^{-}\right) \cup\left(\gamma_{1}^{+}, \gamma_{2}^{-}\right) \cup\left(\gamma_{2}^{+}, \beta\right]$ with the eigenvalue parameter appearing linearly in the boundary conditions and with two supplementary transmission conditions. The classical Sturmian theory did not cover such type of many-interval boundary value transmission problems. For the classical Sturm-Liouville problems it is guaranteed that the problem is self-adjoint with compact resolvent, the spectrum is disctrete and consist of eigenvalues and the corresponding eigenfunctions form an orthogonal basis in the well-known Hilbert space $L_{2}[\alpha, \beta]$. But the boundary-value-transmission problems are not self-adjoint and the system of eigenfunctions did not form a basis in the classical Hilbert space $L_{2}[\alpha, \beta]$ in general. Taking in view this fact we suggest a new approach for self-adjoint realization of such type transmission problems. Moreover, we define some new Hilbert spaces to establish positiveness of corresponding operator-pencil. At first we define a concept of generalized eigenfunctions for this kind of spectral problems. In particular it is shown that if the potential $q(x)$ is continuous then the generalized eigenfunctions satisfies the considered problem is the classical sense. Then we introduce to the consideration some compact operators such a way that the considered boundary-valuetransmission problem can be reduced to the appropriate operator-pencil equation. Finally, we prove that this operator-pencil is self-adjoint and positive definite for sufficiently large negative values of the eigenparameter. It is important to note that the obtained results extends classical results associated with regular Sturm-Liouville problems.
\end{abstract}

Keywords: Boundary value problems, eigenfunctions, boundary and transmission conditions, positive operators.

\section{Yeni Tipten Sturm-Liouville Problemlerinin Ürettiği Diferansiyel Operatörlerin Kendine Eşlenikliği ve Pozitivliği}

Özet. Bu makalenin amacı $\left[\alpha, \gamma_{1}^{-}\right) \cup\left(\gamma_{1}^{+}, \gamma_{2}^{-}\right) \cup\left(\gamma_{2}^{+}, \beta\right]$ çok-aralığında tanımlı olan, özdeğer parametresini doğrusal olarak sınır şartlarında bulunduran ve iki tane ek geçişs şartı içeren $-u^{\prime \prime}(x)+q(x) u(x)=\lambda u(x)$ Sturm-Liouville problemini araştırmaktır. Klasik Sturm-Liouville teorisi bu tipten çok-aralıklı sınır-değer-geçiş problemlerini kapsamaktadır. Klasik Sturm-Liouville problemleri için kendine-eşleniklik, rezolventin kompaktlığı, spektrumun diskretliği ve uygun özfonksiyonların iyi bilinen $L_{2}[\alpha, \beta]$ Hilbert uzayında ortogonal baz oluşturma özelliği sağlanmaktadır. Genellikle sınır-değer-geçiş problemleri kendine-eşlenik değildir ve özfonksiyonlar sistemi klasik $L_{2}[\alpha, \beta]$ Hilbert uzayında baz oluşturmuyor. Bunu dikkate alarak, bu tipten geçiş problemlerinin kendine-eşlenik biçimde sonuçlanabilmesi için yeni bir yaklaşım önermişiz. 
Bunun dışında uygun operatör-demetinin pozitivliğini gösterebilmek için bazı yeni Hilbert uzayları tanımladık. İlk olarak bu türden spektral problemlerin genelleştirilmiş özfonksiyonları kavramını tanımladık. Özel olarak gösterdik ki, eğer $q(x)$ potansiyeli sürekli ise, o halde genelleşmiş özfonksiyonlar incelediğimiz problemi klasik anlamda da sağlıyor. Daha sonra bazı kompakt operatörleri öyle tanımladık ki araştırılan sınır-değergeçiş problemlerini uygun operatör demetine dönüştürmek mümkün olsun. Son olarak özdeğer parametresinin mutlak değerce yeteri kadar büyük negativ değerleri için bu operatör demetinin kendine eşlenik ve pozitiv olduğunu ispat ettik. Elde edilen sonuçların düzgün Sturm-Liouville problemlerinin sağladığı klasik sonuçları genelleştirmesi önem arz etmektedir.

Anahtar Kelimeler: Sınır değer problemleri, özfonksiyonlar, sınır ve geçişs şartları, pozitiv operatörler.

\section{INTRODUCTION}

In the present work we consider a Sturm-Liouville equation

$$
-u^{\prime \prime}(x)+q(x) u(x)=\lambda u(x)
$$

on $\left[\alpha, \gamma_{1}^{-}\right) \cup\left(\gamma_{1}^{+}, \gamma_{2}^{-}\right) \cup\left(\gamma_{2}^{+}, \beta\right]$, together with eigendependent boundary conditions at the end-points $x=\alpha$ and $x=\beta$, given by

$$
\begin{gathered}
\kappa_{1} u(\alpha)-\kappa_{3} u^{\prime}(\alpha)-\lambda \kappa_{2} u^{\prime}(\alpha)=0 \\
u^{\prime}(\beta)=0
\end{gathered}
$$

and with transmission conditions at two interior points $x=\gamma_{1}$ and $x=\gamma_{2}$, given by

$$
\begin{aligned}
& u\left(\gamma_{1}^{+}\right)-\tau_{1} u\left(\gamma_{1}^{-}\right)=0 \\
& u^{\prime}\left(\gamma_{1}^{+}\right)-\frac{1}{\tau_{1}} u^{\prime}\left(\gamma_{1}^{-}\right)-u\left(\gamma_{1}^{-}\right)=0 \\
& u\left(\gamma_{2}^{+}\right)-\tau_{2} u\left(\gamma_{2}^{-}\right)=0 \\
& u^{\prime}\left(\gamma_{2}^{+}\right)-\frac{1}{\tau_{2}} u^{\prime}\left(\gamma_{2}^{-}\right)-u\left(\gamma_{2}^{-}\right)=0
\end{aligned}
$$

where $q(x)$ is a real valued function which is continuous in $\mho_{1}=\left(\alpha, \gamma_{1}^{-}\right), \mho_{2}=\left(\gamma_{1}^{+}, \gamma_{2}^{-}\right) \quad \mho_{3}=\left(\gamma_{2}^{+}, \beta\right)$ and has finite limits $q(\alpha+0), q\left(\gamma_{1}^{ \pm} \pm 0\right), q\left(\gamma_{2}^{ \pm} \pm 0\right), q(\beta-0), \lambda$ is a complex spectral parameter, $\kappa_{i}, \tau_{j}(i=1,2,3$ and $j=1,2)$ are real numbers and $\rho=\kappa_{1} \kappa_{2}>0, \tau_{j}>0$.

Some properties of the Sturm-Liouville Problem (1)-(3) has been studied by many authors (see, e.g., [1-4]). The main goal of those papers is the analysis of the spectrum and justification of the eigenfunction expansion. The considerations of $[2,4]$ are based on the operator-theoretic formulation of the Sturm-Liouville problem (1)-(3). The discrete version of this problem was dealt with by Harmsen and Li [5], Atkinson [6]. The boundary value problem with the parameter appearing nonlinearly in the boundary conditions is also important and has a variety of applications. The continuous version of this problem was dealt with by Binding et al. [7-8], Greenberg and Babuska [9]. Oscillation and comparison results have been obtained in [7]. The completeness of the eigenfunctions and eigenfunction expansions in various function spaces for the Sturm-Liouville problems with spectral parameter in the boundary conditions have been considered in [10-16]. Problems with various singularities have been analyzed in [17-19, 20-30]. 
In different areas of applied mathematics and physics many problems arise in the form of boundary value problems involving transmission conditions at the interior singular points. Such problems are called boundary-value-transmission problems. This kind of problems arise in various problems of mathematics and physics as well as in applications. For example, some boundary value problems with transmission conditions arise in heat and mass transfer problems [31], in vibrating string problems [32], in diffraction problems [33] and etc. The basis properties and eigenfunction expansions in various function spaces of the eigenfunction of the Sturm-Liouville problems with spectral parameter in the boundary conditions have been considered in [10-13, 31, 34]. The concept of generalized solutions in a Hilbert space (see, [34]) allows the eigenvalue problem to be reduced to an operator-pencil equation. In suitable Hilbert space Belinskiy and Dauer in $[10,11]$ have considered the generalized eigenfunctions of a regular SturmLiouville problem on a finite interval with the eigenvalue parameter appearing linearly in the boundary conditions.

It is the aim of this paper is to reduce the boundary-value-transmission problem (1)-(7) to an operator pencil equation

$$
L(\lambda) \psi=0, \quad L(\lambda):=\sum_{i=0}^{n} \lambda^{i} A_{i}
$$

in a corresponding Hilbert space. Weintroduce to the consideration some compact operators such a way that the considered boundary-value problem can be reduced to the appropriate operator-pencil equation and prove that this operator-pencil is self-adjoint and positive definite for sufficiently large negative values of the eigenparameter.

\section{SOME AUXILIARY FACTS}

We use the standard notations for the Hilbert spaces $\underset{i=1}{\oplus} L_{2}\left(\boldsymbol{\mho}_{i}\right), \underset{i=1}{\oplus} H^{1}\left(\boldsymbol{\mho}_{i}\right)$. The inner products in those spaces are given by

$$
\langle u, \vartheta\rangle_{0}=\int_{\alpha}^{\gamma_{1}^{-}} u(x) \bar{\vartheta}(x) d x+\int_{\gamma_{1}^{+}}^{\gamma_{2}^{-}} u(x) \bar{\vartheta}(x) d x+\int_{\gamma_{2}^{+}}^{\beta} u(x) \bar{\vartheta}(x) d x
$$

and

$$
\begin{aligned}
\langle u, \vartheta\rangle_{1} & =\int_{\alpha}^{\gamma_{1}^{-}}\left\{u^{\prime}(x) \overline{\vartheta^{\prime}}(x)+u(x) \bar{\vartheta}(x)\right\} d x \\
& +\int_{\gamma_{1}^{+}}^{\gamma_{2}^{-}}\left\{u^{\prime}(x) \overline{\vartheta^{\prime}}(x)+u(x) \bar{\vartheta}(x)\right\} d x \\
& +\int_{\gamma_{2}^{+}}^{\beta}\left\{u^{\prime}(x) \overline{\vartheta^{\prime}}(x)+u(x) \bar{\vartheta}(x)\right\} d x
\end{aligned}
$$

with the corresponding norms are

$$
\|u\|_{0}=\sqrt{\langle u, u\rangle_{0}}
$$

and 


$$
\|u\|_{1}=\sqrt{\langle u, u\rangle_{0}}
$$

respectively. According to the embedding theorems for the Sobolev spaces ([35]) the functions in $\bigoplus_{i=1}^{3} H^{1}\left(\widetilde{\mho}_{i}\right)$ are continuous on $\mho_{i}$, but their (generalized) derivatives can only be assumed to be elements of $\stackrel{3}{\oplus} L_{i}\left(\widetilde{J}_{i}\right)$.

In below we shall use the following inequalities which can be derived from the well-known embedding theorems for Sopbolev spaces (see, for example ([34])). For any $u \in \oplus_{i=1}^{3} H^{1}\left(\widetilde{\mho}_{i}\right)$, the following inequalities hold

$$
\left|u\left(x_{j}\right)\right|^{2} \leq d_{j}\left\|u^{\prime}\right\|_{0}^{2}+\frac{2}{d_{j}}\|u\|_{0}^{2},
$$

where $j=1,2,3,4, x_{1}=\alpha, x_{2}=\gamma_{1}^{ \pm} \pm 0, x_{3}=\gamma_{2}^{ \pm} \pm 0, x_{4}=\beta$ and $d_{j}(j=1,2,3,4)$ are $\quad$ any positive real numbers are small enough. Moreover, for any $\xi \in \widetilde{\mho}=\widetilde{\mho}_{1} \cup \boldsymbol{\mho}_{2} \cup \widetilde{\mho}_{3}$ the inequality

$$
|u(\xi)| \leq C(\xi)\|u\|_{1}
$$

holds, where the constant $C(\xi)$ is independent of the function $u$, i.e. is dependent only of $\xi$.

Remark 1 Note, the normal derivative of a function $u \in \bigoplus_{i=1}^{3} H^{1}\left(\widetilde{\mho}_{i}\right)$, might not be defined as an element of $\oplus_{i=1}^{3} L_{2}\left(\widetilde{\mho}_{i}\right)$.

Remark 2 Without loss of generality the function $q(x)$ can be assumed to be positive on $\mho$. In fact, after the shift of the spectral parameter $\lambda \rightarrow \lambda-h$, where $h=\max q(x)$ for $x \in \mathcal{J}$, the function $q(x)$ can be asumed to be positive eveywhere on $\mho$.

\section{THE CONCEPT OF GENERALIZED EIGENFUNCTION}

Let us introduce to the consideration a new Hilbert space $\Xi$ which is the main Hilbert space considered in the remainder of this article.

Definition 1 The inner product in the Hilbert space $\Xi=\bigoplus_{i=1}^{3} H^{1}\left(\widetilde{\mho}_{i}\right) \oplus \mathbb{C}$ is defined by

$$
\langle U, V\rangle_{\Xi}=\langle u(x), \vartheta(x)\rangle_{\oiint_{i=1}^{3} H^{1}\left(\mho_{i}\right)}+u_{1} \bar{\vartheta}_{1}
$$

for $U, V \in \Xi$, where $u(x), \vartheta(x) \in \oplus_{i=1}^{3} H^{1}\left(\mho_{i}\right)$ and $u_{1}, \vartheta_{1} \in \mathbb{C}$. 
For further investigation we shall introduce a new inner product on the same linear space $\bigoplus_{i=1}^{3} H^{1}\left(\widetilde{\mho}_{i}\right)$ as follows:

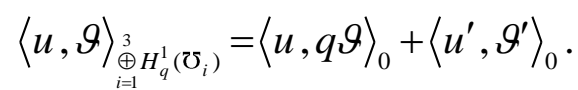

Since $q(x)$ is bounded, positively defined and measurable function, there exist constants $m>0$ and $M>0$ such that

$$
m\|u\|_{1}<\|u\|_{\oplus_{i=1}^{3} H^{1}\left(\mho_{i}\right)}<M\|u\|_{1}
$$

for all $u(x) \in \bigoplus_{i=1}^{3} H^{1}\left(\boldsymbol{\mho}_{i}\right)$

Consequently the inner product (11) generates a norm that is equivalent to the standard norm produced by (8) and therefore the inner product space $\oplus_{i=1}^{3} H^{1}\left(\mho_{i}\right)$ is also Hilbert space.

Now we shall define a concept of generalized solution which is fundamental to this work. The definition of a generalized solutions of the Sturm-Liouville problem (1)-(7) follows by the known procedure (see [34], [36]). Multiplying equation (1) by a conjugate to an arbitrary function $\vartheta(x) \in \bigoplus_{i=1}^{3} H^{1}\left(\mho_{i}\right)$ and integrate by parts over the intervals $\mho_{i}(i=1,2,3)$ and applying the boundary and transmission conditions (2)-(7), we can reduce it to the integral form

$$
\begin{aligned}
& \int_{\mho_{1}}\left\{u^{\prime}(x) \overline{\vartheta^{\prime}}(x)+q(x) u(x) \bar{\vartheta}(x)\right\} d x+\int_{\mho_{2}}\left\{u^{\prime}(x) \overline{\vartheta^{\prime}}(x)+q(x) u(x) \bar{\vartheta}(x)\right\} d x \\
+ & \int_{\mho_{3}}\left\{u^{\prime}(x) \overline{\vartheta^{\prime}}(x)+q(x) u(x) \bar{\vartheta}(x)\right\} d x+\tau_{1} u\left(\gamma_{1}^{-}\right) \bar{\vartheta}\left(\gamma_{1}^{-}\right)+\tau_{2} u\left(\gamma_{2}^{-}\right) \bar{\vartheta}\left(\gamma_{2}^{-}\right)+u^{\prime}(\alpha) \bar{\vartheta}(\alpha) \\
= & \lambda\left\{\int_{\mho_{1}} u(x) \bar{\vartheta}(x) d x+\int_{\mho_{2}} u(x) \bar{\vartheta}(x) d x+\int_{\mho_{3}} u(x) \bar{\vartheta}(x) d x\right\} .
\end{aligned}
$$

According to the structure of the space $\bigoplus_{i=1}^{3} H^{1}\left(\mho_{i}\right)$ the values of derivatives at a point should be excluded from the idntity (12).

Denoting $\omega:=\kappa_{2} u^{\prime}(\alpha)$ and taking in view the boundary condition (2), we have $u^{\prime}(\alpha)=\frac{\omega}{\kappa_{2}}$. Then the boundary condition (2) can be written in the following form: $\kappa_{1} u(\alpha)-\kappa_{3} u^{\prime}(\alpha)=\lambda \omega$.

Taking in view the last relation it is easy to see that the first boundary condition (2) takes the form

$$
\frac{u(\alpha)}{\kappa_{2}}-\frac{\kappa_{3}}{\kappa_{2}} \frac{\omega}{\rho}=\lambda \frac{\omega}{\rho}
$$

Putting $u^{\prime}(\alpha)=\frac{\omega}{\kappa_{2}}$ in the integral identity (17), we obtain 


$$
\langle u, \vartheta\rangle_{\substack{\oplus=1 \\ \mathcal{H}_{1}^{1}\left(\mho_{i}\right)}}+\tau_{1} u\left(\gamma_{1}^{-}\right) \bar{\vartheta}\left(\gamma_{1}^{-}\right)+\tau_{2} u\left(\gamma_{2}^{-}\right) \bar{\vartheta}\left(\gamma_{2}^{-}\right)+\frac{\omega}{\kappa_{2}} \bar{\vartheta}(\alpha)=\lambda\langle u, \vartheta\rangle_{0} .
$$

Thus the integro-differential equation (12) is transformed into the system of equalities (13)-(14) all terms of which are defined for the $u, \vartheta \in \underset{i=1}{\stackrel{3}{1}} H^{1}\left(\widetilde{\mho}_{i}\right)$.

Now we are ready to introduce a concept of generalized solution for the problem under consideration.

Definition 2 The two-component element $(u(x), \omega)$ of the Hilbert space $\Xi$ is said to be a generalized solution of the Sturm-Liouville problem (1)-(7), if this element satisfy the equations (13) and (14) for any $\vartheta \in \underset{i=1}{\stackrel{3}{1}} H^{1}\left(\mho_{i}\right)$.

The concept of the generalized solution is based on the following result.

Lemma 1 Let the function $u$ is twice continuously differentiable and the function $q$ continuously on $\mho$. Then the generalized solution of the Sturm-Liouville problem satisfies equations (1)(7) in the classical sense.

Consequently the concept of generalized solution is an extension of a classical solution.

\section{OPERATOR-PENCIL REALIZATION OF THE PROBLEM}

The reduction of identities (13)-(14) to an operator-pencil equation is based on the following result.

Lemma 2 For the bilinear functionals

$$
\begin{aligned}
& \ell_{1}(u, \vartheta):=\tau_{1} u\left(\gamma_{1}^{-}\right) \bar{\vartheta}\left(\gamma_{1}^{-}\right)+\tau_{2} u\left(\gamma_{2}^{-}\right) \bar{\vartheta}\left(\gamma_{2}^{-}\right) \\
& \ell_{2}(u, \vartheta):=\langle u, \vartheta\rangle_{0}
\end{aligned}
$$

and

$$
\ell_{3}(\omega, \vartheta):=\frac{\omega}{\kappa_{2}} \bar{\vartheta}(\alpha)
$$

there are such bounded linear operators $\mathrm{T}_{1}, \mathrm{~T}_{2}$ and $\mathrm{T}_{3}$ respectively such that

$$
\ell_{k}(u, \vartheta)=\left\langle\mathrm{T}_{k} u, \vartheta\right\rangle_{\substack{\oplus=1 \\ i=1}}^{3}\left(\mho_{i}\right) \text { for } k=1,2
$$

and

$$
\ell_{3}(\omega, \vartheta)=\left\langle\mathrm{T}_{3} \omega, \vartheta\right\rangle_{\substack{\oplus=1 \\ \mathcal{H}_{1}}} H_{\left(\mho_{i}\right)} \text { for } k=3
$$

Moreover the operators $\mathrm{T}_{1}, \mathrm{~T}_{2}: \bigoplus_{i=1}^{3} H^{1}\left(\boldsymbol{\mho}_{i}\right) \rightarrow \bigoplus_{i=1}^{3} H^{1}\left(\boldsymbol{\mho}_{i}\right)$ and $\mathrm{T}_{3}: \mathbb{C} \rightarrow \bigoplus_{i=1}^{3} H^{1}\left(\boldsymbol{\mho}_{i}\right)$ are compact, the operators $\mathrm{T}_{1}$ and $\mathrm{T}_{2}$ are selfadjoint and positive. 
Proof. The functionals $\ell_{k}(k=1,2,3)$ allows the following obvious estimates:

$$
\begin{aligned}
& \left|\ell_{1}(u, \vartheta)\right| \leq C_{1}\left\{\left|\tau_{1}\right|\left|u\left(\gamma_{1}^{-}\right)\right|\left|\bar{\vartheta}\left(\gamma_{1}^{-}\right)\right|+\left|\tau_{2}\right|\left|u\left(\gamma_{2}^{-}\right)\right|\left|\bar{\vartheta}\left(\gamma_{2}^{-}\right)\right|\right\}, \\
& \left|\ell_{2}(u, \vartheta)\right| \leq C_{2}\|u\|\|\vartheta\|,
\end{aligned}
$$

and

$$
\left|\ell_{3}(\omega, \vartheta)\right| \leq C_{3}|\omega||\vartheta(\alpha)|
$$

Here and below $C_{k}(k=1,2, \ldots)$ denote different positive constant whose exact values are not important for the proof.

The inequality (9)-(10) imply

$$
\|u\| \leq C_{4}\|u\|_{\|_{i=1}^{3} H_{q}^{1}\left(\mho_{i}\right)}^{3}
$$

and

$$
|u(d)| \leq C_{5}\|u\|_{\Theta_{i=1}^{3} H_{q}^{1}\left(\mho_{i}\right)} \text { for any } d \in \mho_{i} .
$$

Hence, the functionals $\ell_{k}(k=1,2,3)$ allows the following estimate:

$$
\begin{aligned}
& \left|\ell_{1}(u, \vartheta)\right| \leq C_{6}\|u\|_{\underbrace{3}_{i=1} H_{q}^{1}\left(\mho_{i}\right)}\|\vartheta\|_{\underbrace{3}_{i=1} H_{q}^{1}\left(\mho_{i}\right)}, \\
& \left|\ell_{2}(u, \vartheta)\right| \leq C_{7}\|u\|_{\underbrace{3}_{i=1} H_{q}^{1}\left(\mho_{i}\right)}\|\vartheta\|_{\Theta_{i=1}^{3} H_{q}^{1}\left(\mho_{i}\right)}, \\
& \left|\ell_{3}(\omega, \vartheta)\right| \leq C_{8}|\omega|\|\vartheta\|_{\underbrace{3}_{i=1} H_{q}^{1}\left(\sigma_{i}\right)} .
\end{aligned}
$$

Thefore, $\ell_{k}(k=1,2,3)$ are linear functionals in $\vartheta \in \underset{i=1}{\oplus} H^{1}\left(\mho_{i}\right)$ for any given $u \in \oplus_{i=1}^{3} H^{1}\left(\mho_{i}\right), k=1,2$, and $\omega \in \mathbb{C}, k=3$, respectively. The Riesz representation theorem shows that the representations (15)-(17) are valid for some bounded operators $\mathrm{T}_{k}(k=1,2,3)$. The selfadjointness and positiveness of the operators $T_{1}$ and $T_{2}$ are obvious. The compactness of $T_{2}$ is well-known fact (see, [34]). The proof of the compactness of $T_{1}$ can be found by using the same arguments, as in $[10,11]$ and [13].

Now the compactness of the operator $\mathrm{T}_{3}$ will be proven. It is easy to verify that the adjoint operator of $\mathrm{T}_{3}$ is defined on whole $\underset{i=1}{\oplus} H^{1}\left(\mho_{i}\right)$ with equality $\mathrm{T}_{3}^{*} u=\frac{1}{\kappa_{2}} u(\alpha)$. From this representation it follows that, the operator $\mathrm{T}_{3}^{*}$ from $\bigoplus_{i=1}^{3} H^{1}\left(\widetilde{\mho}_{i}\right)$ to $\mathbb{C}$ are bounded, i.e

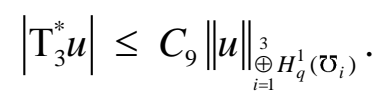

Consequently the operator $\mathrm{T}_{3}^{*}$ is bounded linear operator with finite dimensional range and therefore is compact. 
Then by virtue of well-known theorem of Functional Analysis (see, for example [37]) the operator $\mathrm{T}_{3}$ is also compact. The proof is complete.

Lemma 3 The generalized eigenfunctions of the Sturm-Liouville problem (1)-(7) satisfy the following operator polynomial equation in $\Xi$

$$
\begin{aligned}
& L(\lambda) \Phi=0, \quad L(\lambda)=L_{1}-\lambda L_{2} \\
& L_{1}=\left(\begin{array}{cc}
I+\mathrm{T}_{1} & \mathrm{~T}_{3} \\
\mathrm{~T}_{3}^{*} & -\frac{\kappa_{3}}{\kappa_{2} \rho} I
\end{array}\right), \quad L_{2}=\left(\begin{array}{cc}
\mathrm{T}_{2} & 0 \\
0 & \frac{1}{\rho} I
\end{array}\right) .
\end{aligned}
$$

Here $I$ is the identity operator and the space $\Xi$ is described in Definitionl and $\Phi=\left(\begin{array}{lll}u(x) & \omega\end{array}\right)$.

Proof. By using Lemma 2 the identities (13)-(14) can be rewritten as follows

$$
\begin{gathered}
\langle u, \vartheta\rangle_{\substack{\oplus=1 \\
i=1}}^{3} H_{q}^{1}\left(\mho_{i}\right) \\
\mathrm{T}_{3}^{*} u-\frac{\kappa_{3}}{\kappa_{2}} \frac{\omega}{\rho}=\lambda \frac{\omega}{\rho} .
\end{gathered}
$$

The arbitrariness of $\vartheta \in \bigoplus_{i=1}^{3} H^{1}\left(\widetilde{\mho}_{i}\right)$ implies

$$
u+\mathrm{T}_{1} u+\mathrm{T}_{3} \omega=\lambda \mathrm{T}_{2} u
$$

and hence, the proof is complete.

\section{SELFADJOINTNESS AND POSITIVENESS OF THE CORRESPONDING OPERATOR- PENCIL}

Theorem 1 The operators $L_{1}$ and $L_{2}$ are self-adjoint in the Hilbert space $\Xi$.

Proof. Let $\Phi_{1}=(u(),. \omega)$ and $\Phi_{2}=\left(v(),. \omega^{\prime}\right)$ be any two element of $\Xi$. Then making use of the representation $\mathrm{T}_{3}^{*} u=\frac{1}{\kappa_{2}} u(\alpha)$ from (15)-(18) and (19) we have

$$
\begin{aligned}
& \left\langle L_{1} \Phi_{1}, \Phi_{2}\right\rangle_{\Xi}=\left\langle u+\mathrm{T}_{1} u+\mathrm{T}_{3} \omega, v\right\rangle_{i=1}^{\underset{\oplus}{3} H_{q}^{1}\left(\mho_{i}\right)}+\left(\mathrm{T}_{3}^{*} u-\frac{\kappa_{3}}{\kappa_{2}} \frac{\omega}{\rho}\right) \overline{\omega^{\prime}} \\
& \left\langle\Phi_{1}, L_{1} \Phi_{2}\right\rangle_{\Xi}=\overline{\left\langle L_{1} \Phi_{2}, \Phi_{1}\right\rangle_{\Xi}}=\overline{\left\langle v+\mathrm{T}_{1} v+\mathrm{T}_{3} \omega^{\prime}, u\right\rangle_{i=1}^{\Theta_{q} H_{q}^{1}\left(\mho_{i}\right)}}+\overline{\left(\mathrm{T}_{3}^{*} v-\frac{\kappa_{3}}{\kappa_{2}} \frac{\omega^{\prime}}{\rho}\right)} \bar{\omega} .
\end{aligned}
$$

Substracting (21) from (20) and realizing that

$$
\left\langle\mathrm{T}_{i} \omega, v\right\rangle_{i=1}^{\beta_{i=1}^{1} H_{q}^{1}\left(\mho_{i}\right)}=\omega \overline{\left(\mathrm{T}_{i}^{*} v\right)} \quad \text { and } \quad \mathrm{T}_{i}^{*} u \overline{\omega^{\prime}}=\left\langle u, \mathrm{~T}_{i} \omega^{\prime}\right\rangle_{\Xi}
$$

by definition of the adjoint operator, we see that 


$$
\left\langle L_{1} \Phi_{1}, \Phi_{2}\right\rangle_{\Xi}-\left\langle\Phi_{1}, L_{1} \Phi_{2}\right\rangle_{\Xi}=0
$$

so the operator $L_{1}$ is self-adjoint in the Hilbert space $\Xi$. Similarly we have

$$
\begin{aligned}
& \left\langle L_{2} \Phi_{1}, \Phi_{2}\right\rangle_{\Xi}=\left\langle\mathrm{T}_{2} u, v\right\rangle_{\underbrace{3}_{i=1} H_{q}^{1}\left(\mho_{i}\right)}+\frac{\omega \overline{\omega^{\prime}}}{\rho^{2}},
\end{aligned}
$$

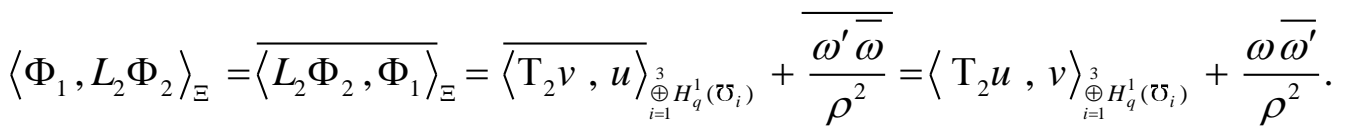

Consequently,

$$
\left\langle L_{2} \Phi_{1}, \Phi_{2}\right\rangle_{\Xi}-\left\langle\Phi_{1}, L_{2} \Phi_{2}\right\rangle_{\Xi}=0
$$

so the operator $L_{2}$ is self-adjoint in the Hilbert space $\Xi$. The operators $L_{1}$ and $L_{2}$ are also compact in the Hilbert space $\Xi$, which completes the proof.

Corollary 1 The operator $L(-\lambda)=L_{1}+\lambda L_{2}$ is self-adjoint for each real $\lambda$.

Remark 3 Let $\lambda \in \mathbb{C}$ be any eigenvalue with the generalized eigenfunction $\tilde{u}(x, \lambda):=(u(x, \lambda), \omega)$. Then the operator polynomial equation $L(-\lambda) \tilde{u}(., \lambda)=0$ is hold in the Hilbert space $\Xi$.

Lemma 4 The inequality

$$
2\left|\operatorname{Re}\left(\int_{\mho} u(x) \bar{\vartheta}(x) d x\right)\right| \leq\|u\|^{2}+\|\vartheta\|^{2}
$$

is hold for any $u, \vartheta \in \bigoplus_{i=1}^{3} L_{2}\left(\widetilde{\mho}_{i}\right)$.

Proof. The inequality (22) is a direct consequence of the polar identity.

Now, making use the Lemma 2, Theorem 1 and inequality (22) we have the following important result.

Theorem 2 There exists $\mu>0$ such that for each real $\lambda_{0}>\mu$, the operators $L\left(-\lambda_{0}\right)$ is positive defined in the Hilbert space $\Xi$, that is for real positive $\lambda_{0}$ large enough, there exists a constant $C=C\left(\lambda_{0}\right)>0$ depending only of parameter $\lambda_{0}$, such that

$$
\left\langle L\left(-\lambda_{0}\right) \Phi, \Phi\right\rangle_{\Xi} \geq C\left(\lambda_{0}\right)\|\Phi\|_{\Xi}^{2}
$$

for all $\Phi \in \Xi$. 


\section{REFERENCES}

[1]. C. T. Fulton, Two-point boundary value problems with eigenvalue parameter contained in the boundary conditions, Proc. R. Soc. Edinburgh, A77(1977), 293-308.

[2]. D. B. Hinton, An expansion theorem for an eigenvalue problem with eigenvalue parameter contained in the boundary condition, Quart. J. Math. Oxford, 30(1979), 33-42.

[3]. A. Schneider, A Note on Eigenvalue Problems with Eigenvalue Parameter in the Boundary Conditions, Math. Z., 136(1974) 163-167.

[4]. J. Walter, Regular eigenvalue problems with eigenvalue parameter in the boundary conditions. Math. Z. 133(1973), 301-312.

[5]. B. Harmsen, A. Li, Discrete Sturm-Liouville problems with parameter in the boundary conditions, Journal of Difference Equations and Applications, 8(11)(2002), 969-981.

[6]. F. V. Atkinson, Discrete and Continuous Boundary Problems, Academic Press, New York, 1964.

[7]. P. A. Binding, P. J. Browne, Oscillation theory for indefinite Sturm-Liouville problems with eigenparameter dependent boundary conditions, Proc. Roy. Soc. Edinburgh Sect., A 127(1997), 1123-1136.

[8]. P. A. Binding, P. J. Browne and K. Seddighi, Sturm-Liouville problems with eigenparameter dependent boundary conditions, Proc. Edinburgh Math. Soc., 37(2)(1993), 57-72.

[9]. L. Greenberg, I. Babuska, A continuous analogue of Sturm sequences in the context of SturmLiouville problems, SIAM Journal on Numerical Analysis, 26(1989), 920-945.

[10]. B. P. Belinskiy, J. P. Dauer, On a regular Sturm-Liouville problem on a finite interval with the eigenvalue parameter appearing linearly in the boundary conditions, Spectral theory and computational methods of Sturm-Liouville problem. Eds. D. Hinton and P. W. Schaefer, 1997.

[11]. B. P. Belinskiy, J. P. Dauer, Eigenoscillations of mechanical systems with boundary conditions containing the frequency, Quarterly of Applied Math., 56(1998), 521-541.

[12]. N. B. Kerimov, R. Kh. Mamedov, On a boundary value problem with Spectral parameter in the boundary conditions, (Russian) Sibirsk. Mat. Zh. 40, no 2, (1999) pp. 325-335.

[13]. H. Olğar, O. Sh. Mukhtarov, Weak Eigenfunctions Of Two-Interval Sturm-Liouville Problems Together With Interaction Conditions, Journal of Mathematical Physics, 58, 042201 (2017), DOI: 10.1063/1.4979615.

[14]. E. M. Russakovskii, Sturm-Liouville problem with parameter in the boundary conditions, Trudy Seminara imeni I. G. Petrovskogo, 18, 1993.

[15]. A. M. Sarsenbi, A. A. Tengaeva, On the basis properties of root functions of two generalized eigenvalue problems, ISSN 0012-2661, Differential Equations, 2012, Vol. 48, No. 2, pp. 306-308.

[16]. A. A. Shkalikov, On the Basis Problem of the Eigenfunctions of an Ordinary Differential Operators, Uspekhi Mat. Nauk, 34:5 (209)(1979), 235-236.

[17]. R. Kh. Amirov, A. S. Ozkan and B. Keskin, Inverse problems for impulsive Sturm-Liouville operator with spectral parameter linearly contained in boundary conditions, Integral Transforms and Special Functions, 20(8)(2009), 607-618.

[18]. R. Amirov, N. Topsakal, On inverse problem for singular Sturm-Liouville operator with discontinuity conditions, Bull. Iranian Math. Soc. Vol. 40(2014), No. 3, pp. 585-607.

[19]. B. P. Allahverdiev, E. Bairamov and E. Ugurlu, Eigenparameter dependent Sturm Liouville problems in boudary conditions with transmission conditions, J. Math. Anal. Appl. 401(2013), 388396.

[20]. K. Aydemir, H. Olğar, O. Sh. Mukhtarov and F. S. Muhtarov, Differential operator equations with interface conditions in modified direct sum spaces, Filomat, 32:3(2018), 921-931. 
[21]. K. Aydemir, O. Mukhtarov, A Class of Sturm-Liouville Problems with Eigenparameter Dependent Transmission Conditions, Numerical Functional Analysis and Optimization, (2017), Doi:10.1080/01630563.2017.1316995.

[22]. K. Aydemir, O. Sh. Mukhtarov, Second-order differential operators with interior singularity, Advances in Difference Equations, (2015), 2015:26 DOI 10.1186/s13662-015-0360-7.

[23]. Y. Güldü, R. Kh. Amirov and N. Topsakal, On impulsive Sturm-Liouville operators with singularity and spectral parameter in boundary conditions, Ukrainian Mathematical Journal, Vol. 64, No. 12, May,2013 (Ukrainian Original Vol. 64, No. 12, December, 2012), 1816-1838.

[24]. M. Kandemir, O. Sh. Mukhtarov, Nonlocal Sturm-Liouville Problems with Integral Terms in the Boundary Conditions, Electronic Journal of Differential Equations, Vol. 2017 (2017), No. 11, pp. $1-12$.

[25]. O. Sh. Mukhtarov, K. Aydemir, Eigenfunction expansion for Sturm-Liouville problems with transmission conditions at one interior point, Acta Mathematica Scientia, 35B(3)(2015), 639-649.

[26]. O. Sh. Mukhtarov, K. Aydemir, The Eigenvalue Problem with Interaction Conditions at One Interior Singular Point, Filomat 31:17(2017), 5411-5420.

[27]. O. Sh. Mukhtarov, H. Olğar and K. Aydemir, Resolvent Operator and Spectrum of New Type Boundary Value Problems, Filomat, 29:7(2015), 1671-1680.

[28]. O. Sh. Mukhtarov, M. Kandemir, Asymptotic behaviour of eigenvalues for the discontinuous boundary-value problem with Functional-Transmissin conditions, Acta Mathematica Scientia, 22B(3)(2002), pp.335-345.

[29]. A. S. Ozkan, B. Keskin and Y. Cakmak, Double discontinuous inverse problems for SturmLiouville operator with parameter-dependent conditions, Abstract and Applied Analysis, 2013, Article ID 794262, P.7.

[30]. E. S. Panakhov, T. Gulsen, On discontinuous Dirac systems with eigenvalue dependent boundary conditions, AIP Conference Proceeding, 1648, 260003(2015), 1-4, https://doi.org/10.1063/1.4912520.

[31]. A. V. Likov, Yu. A. Mikhailov, The Theory Of Heat And Mass Transfer, Qosenergaizdat (Russian), 1963.

[32]. A. N. Tikhonov, A. A. Samarskii, Equations Of Mathematical Physics, Oxford and New York, Pergamon, 1963.

[33]. N. N. Voitovich, B. Z. Katsenelbaum and A. N. Sivov, Generalized Method Of Eigen-Vibration In The Theory Of Diffraction, Nakua, Moskow (Russian), 1997.

[34]. O. A. Ladyzhenskaia, The Boundary Value Problems of Mathematical Physics, Springer-Verlag, New York, 1985.

[35]. I. C. Gohberg, M. G. Krein, Introduction to The Theory of Linear Non-Selfadjoint Operators, Translation of Mathematical Monographs, vol. 18, Amer. Math. Soc., Providence, Rhode Island, 1969.

[36]. D. Gilbarg, N. S. Trudinger, Elliptic partial differential equations of second order, 2nd ed. SpringerVerlag, Berlin, 1983.

[37]. E. Kreyszig, Introductory Functional Analysis With Application, New-York, 1978. 